\title{
Map- vs. homology-based cloning for the recessive gene ol-2 conferring resistance to tomato powdery mildew
}

\author{
Stefano Pavan $\cdot$ Zheng Zheng $\cdot$ Mariya Borisova $\cdot$ Petra van den Berg $\cdot$ \\ Concetta Lotti · Claudio De Giovanni · Pim Lindhout · Hans de Jong • \\ Luigi Ricciardi $\cdot$ Richard G. F. Visser $\cdot$ Yuling Bai
}

Received: 15 June 2007 / Accepted: 10 September 2007 / Published online: 4 December 2007

(C) The Author(s) 2007

\begin{abstract}
The recessive gene ol-2 confers papillaassociated and race-non-specific resistance to tomato powdery mildew caused by Oidium neolycopersici. In order to facilitate marker assisted selection (MAS) in practical breeding programmes, we identified two simple sequence repeat (SSR) markers and one cleaved amplified polymorphic sequence (CAPS) marker which are linked to the resistance locus and co-dominantly inherited. Aiming to provide a base for ol-2 positional cloning, we used a large segregating $\mathrm{F}_{2}$ population to merge these markers with all the ol-2 linked amplified fragment length polymorphism $\left(\mathrm{AFLP}^{\circledR}\right)$ markers previously identified in an inte-
\end{abstract}

S. Pavan - Z. Zheng $\cdot$ P. van den Berg $\cdot$ P. Lindhout .

R. G. F. Visser · Y. Bai ( $\square)$

Laboratory of Plant Breeding, Wageningen University,

Droevendaalsesteeg 1, 6708 PB Wageningen,

The Netherlands

e-mail: bai.yuling@wur.nl

S. Pavan · C. De Giovanni - L. Ricciardi

Department of Agroforestry, Environmental Biology and

Chemistry, Section of Genetics and Plant Breeding,

University of Bari, Via Amendola 165/A, Bari, 70126, Italy

M. Borisova $\cdot$ H. de Jong

Laboratory of Genetics, Wageningen University,

Arboretumlaan 4, 6703 BD Wageningen, The Netherlands

C. Lotti

Department of Agro-Environmental Science, Chemistry and Crop Protection, University of Foggia, Via Napoli 25, Foggia 71100, Italy grated genetic map. By screening a tomato bacterial artificial chromosome (BAC) library, we detected two BAC clones containing two expressed sequence tags (ESTs) homologous to the gene $m l o$, responsible for powdery mildew resistance in barley, as well as an ol2-linked marker. Chromosomal mapping by Fluorescence in situ Hybridization (FISH) revealed major signals of the two BAC DNAs in the pericentromeric heterochromatin of the short arm of chromosome 4 , in the same region where the ol-2 gene was previously mapped. The genetic and cytogenetic co-localisation between $o l-2$ and tomato $m l o$-homologue(s), in addition to the similarity of $o l-2$ and $m l o$ resistances for both genetic and phytopathological characteristics, suggests that $o l-2$ is likely a mlo-homologue. Thus, a homology-based cloning approach could be more suitable than positional cloning for $\mathrm{ol}-2$ isolation.

Keywords Fluorescence in situ hybridization . Homology-based cloning · Integrated linkage map · Map-based cloning · Oidium neolycopersici . Solanum lycopersicum

\section{Introduction}

Tomato powdery mildew caused by Oidium neolycopersici has recently been recognized as a worldwide emerging pathogen on tomato (Jones et al. 2001; Kiss et al. 2001). Several dominant genes have been characterized, which confer resistance to 
O. neolycopersici and originate from wild tomato species (Bai et al. 2005; Kozik 1993; Lindhout et al. 1994). The exploitation of these genes in plant breeding is limited due to linkage drag phenomena, consisting in unfavourable wild alleles closely linked to the resistance loci (Zeven et al. 1983; Young and Tanksley 1989). In addition, resistance conferred by the dominant $\mathrm{Ol}$-genes is based on race-specific hypersensitive response (HR), thus is likely not durable. In contrast, the recessive gene $o l-2$, located around the centromere of chromosome 4 (De Giovanni et al. 2004), derives from the germplasm of the cultivated tomato species, Solanum lycopersicum (Ciccarese et al. 1998), and confers race-non-specific resistance via papilla formation, a non-HR-based mechanism (Bai et al. 2005).

The introduction of $\mathrm{ol}-2$ resistance into tomato cultivars via traditional breeding methods is complicated by its recessive nature, as the selection of the ol-2 allele needs to be tested in the selfing progeny of each backcross generation. Although marker assisted selection (MAS) with co-dominant molecular markers would allow the breeder to perform the selection of the ol-2 allele in backcross generations, the low genetic variation within S. lycopersicum (Miller and Tanksley 1990) hindered the identification of polymorphic co-dominant markers linked to the resistance locus. So far, mainly amplified fragment length polymorphism $\left(\right.$ AFLP $\left.^{\circledR}\right)$ markers have been identified for the ol-2 region (De Giovanni et al. 2004; Ricciardi et al. 2007). In practical breeding, AFLP ${ }^{\circledR}$ markers cannot offer efficient MAS as they are dominant and require advanced equipment. Moreover, AFLP ${ }^{\circledR}$ markers are patented and thus not utilizable by most breeding companies. Although several efforts were made, the conversion of $o l-2$ linked AFLP ${ }^{\circledR}$ markers into PCR markers failed (Ricciardi et al. 2007).

Similarly to ol-2, the barley gene mlo (Büschges et al. 1997) is recessively inherited and confers durable resistance to barley powdery mildew (Blumeria graminis f. sp. hordei) through the apposition of papillae at the cell wall (Piffanelli et al. 2002). The similarity of $\mathrm{ol}-2$ and $\mathrm{mlo}$ resistances for both genetic (recessive) and phytopathological (papilla-based mechanism) characteristics may indicate that ol-2 confers mlo-based durable resistance.

In the present work, several attempts were carried out in order to obtain new simple PCR co-dominant markers linked to $\mathrm{ol}-2$, allowing selection of the resis- tance via MAS. Aiming at ol-2 positional cloning, a segregating $\mathrm{F}_{2}$ population of 316 individuals was analyzed to generate an integrated map of the $o l-2$ region, including all the dominant AFLP $^{\circledR}$ markers reported so far. Bacterial artificial chromosome (BAC) library screening and Fluorescence in situ Hybridization (FISH) were used to investigate the possibility that $o l$ 2 resistance is mediated by a $m l o$-based mechanism.

\section{Materials and methods}

Plant material

A $F_{2}$ mapping population of 316 individuals was used, which was derived from a cross between the resistant $\mathrm{F}_{3}$ line $\mathrm{R} 28$ and the susceptible S. lycopersicum cv. Moneymaker (MM). The $\mathrm{F}_{3}$ line R28 (homozygous for the ol-2 allele) was developed from a cross between the resistant line LC-95 of S. lycopersicum var. cerasiforme and the susceptible S. lycopersicum cv. Super Marmande (SM) (Ciccarese et al. 1998).

Fungal material and disease test

The O. neolycopersici used in this study was collected from infected tomato plants in The Netherlands. One-month old plants were inoculated with a suspension of conidia as described by Bai et al. (2003). The inoculated plants were grown in a greenhouse compartment at $20 \pm 2{ }^{\circ} \mathrm{C}$ with $70 \pm 15 \%$ relative humidity $(\mathrm{RH})$ and day-length of $16 \mathrm{~h}$. Disease evaluation was carried out twice, 12 and 15 days postinoculation (dpi), on the basis of presence or absence of fungal sporulation.

Marker analysis

Total DNA was extracted from plant leaves 2 days before inoculation by using a rapid cetyl trimethyl ammonium bromide (CTAB) isolation method (Brugmans et al. 2003).

Seven simple sequence repeat (SSR) markers on tomato chromosome 4 were chosen among the ones published by Suliman-Pollatschek et al. (2002) (Table 1). PCR reactions $(10 \mu \mathrm{l})$ contained $50 \mathrm{ng}$ of genomic DNA, $1 \times$ PCR buffer, 0.5 pmol of each forward and reverse primer (one of which was labelled 
with IRD700 or IRD800), $0.2 \mathrm{mM}$ dNTPs and 0.5 units of Taq-polymerase in demi water. PCR conditions were: 1 cycle at $94^{\circ} \mathrm{C}$ for 3 min followed by 30 cycles of $30 \mathrm{~s}$ at $94^{\circ} \mathrm{C}, 45 \mathrm{~s}$ at the optimal annealing temperature, $45 \mathrm{~s}$ at $72^{\circ} \mathrm{C}$, and a final extension of $7 \mathrm{~min}$ at $72^{\circ} \mathrm{C}$. Amplified products were scored on $6 \%$ polyacrylamide gel with a LICOR 4200 DNA sequencer and on $2.5 \%$ agarose gel stained with ethidium bromide.

The cleaved amplified polymorphic sequence (CAPS) marker U3-2HhaI (Table 1) was obtained by designing primers on the SCAU3 ${ }_{1500}$ sequence characterized amplified region (SCAR) sequence reported by De Giovanni et al. (2004) with the software Primer3 (Rozen and Skaletsky 2000) and digesting the amplification products with different restriction enzymes. PCR and digestion were carried out according to the conditions reported by Bai et al. (2003).

Nine markers with known sequence mapped on tomato chromosome 4 and two tomato expressed sequence tag (EST) sequences (cLEC-80-N18 and cTOC-20-K10) homologous to the barley mlo gene were selected from the Sol Genomics Database (http:// www.sgn.cornell.edu, Table 1). Locus specific primers were designed to amplify genomic DNA as described by Bai et al. (2003). All the amplification products were subsequently digested with several restriction enzymes as described by Bai et al. (2004). AFLP $^{\circledR}$ fingerprints of the ol-2 linked markers identified by De Giovanni et al. (2004) and Ricciardi et al. (2007) were generated on a LICOR 4200 DNA sequencer as described by Bai et al. (2003).

\section{Linkage analysis}

The software JoinMap 3.0 (Van Ooijen and Voorrips 2001) was used to generate an integrated linkage map of the ol-2 chromosomal region. A logarithm of odds (LOD) score of 4.0 was used as linkage threshold and the Kosambi mapping function was used to convert recombination frequency into genetic map distance.

BAC screening and fluorescence in situ hybridization

The HindIII BAC library of S. lycopersicum cv. Heinz 1706 (Budiman et al. 2000) was screened for the presence of the tomato mlo-homologous EST sequences cLEC-80-N18 and cTOC-20-K10 and the ol-2 linked SCAR sequence U3-2. The screening was performed by PCR with corresponding primers and conditions presented in Table 1.

FISH of the BACs 184L18 and 205G16 on pachytene complements was performed as described by Zhong et al. (1999) and Chang (2004). In brief: flower buds of tomato cv. Tiny Tim containing anthers at meiotic prophase I were fixed in ethanol-acetic acid (1:3). After digesting the cell walls with a pectolytic enzyme mix, cells were spread in acetic acid $45 \%$ and post-fixed in ethanol-acetic acid (3:1). BAC clones 184L18 and 205G16 were directly labelled with FITC-dUTP and Cy3.5-dCTP, respectively. The probes were hybridized on the cell complements together with excess of Cot100 genomic DNA for blocking repetitive DNA sequences. The slides were counterstained with DAPI and studied under a fluorescence microscope with a high-sensitive CCD camera. Image capturing and analysis followed the procedures as described by Chang (2004).

\section{Results}

Disease test

A disease test was performed on the 316 individuals of the $\mathrm{F}_{2}$ population of $\mathrm{MM} \times \mathrm{R} 28$. Ten $\mathrm{MM}$ and ten R28 plants were used as susceptible and resistant controls, respectively. Ten days post-inoculation all the MM plants showed powdery mildew sporulation on the upper side of the leaves, whereas no symptoms could be detected on R28 individuals. The $F_{2}$ population was rated for resistance at 12 and $15 \mathrm{dpi}$. In total, there were 240 susceptible and 76 resistant $F_{2}$ individuals, which fit into the expected 3:1 ratio for a single recessive gene model $\left(\chi^{2}=0.152\right)$.

An integrated map for the chromosomal region harbouring ol-2

Aiming to fine-map the ol-2 gene, we designed primers for nine chromosome 4 specific sequences located in the region bearing ol-2 (Table 1). All the primer pairs amplified monomorphic fragments between MM and R28, which were then digested with different restriction enzymes. Unfortunately, no CAPS polymorphism was detected.

SSR markers have been reported to be powerful in detecting polymorphisms within S.lycopersicum. 
Table 1 Markers tested to reveal polymorphisms between the parental lines Solanum lycopersicum cv. MM and R28

\begin{tabular}{|c|c|c|c|c|c|}
\hline Marker name & Type & Source & Primers sequence $\left(5^{\prime} \rightarrow 3\right)$ & Size $(b p)$ & $\operatorname{Tm}\left({ }^{\circ} \mathrm{C}\right)$ \\
\hline Tom 316 & SSR & Suliman-Pollatschek et al. 2002 & $\begin{array}{l}\text { GAGTTGTTCTTTGGTTGTTT } \\
\text { TAGATTTTTCGTGTAGATGT }\end{array}$ & $134+138$ & 50 \\
\hline Tom 332 & SSR & Suliman-Pollatschek et al. 2002 & $\begin{array}{l}\text { GATACCATTAAAGCTCATTC } \\
\text { GGTTTCCGTCATTATGTCAG }\end{array}$ & $115+120$ & 50 \\
\hline Tom95-96 & SSR & Suliman-Pollatschek et al. 2002 & $\begin{array}{l}\text { GTGGATGGATATGTGTGA } \\
\text { GCACGGTAGGTCGCAGGCA }\end{array}$ & - & 46 \\
\hline Tom268-269 & SSR & Suliman-Pollatschek et al. 2002 & $\begin{array}{l}\text { AGGGTATGAGATGAGACAAT } \\
\text { TTTTACCTTCTTTACTTGGA }\end{array}$ & - & 48 \\
\hline Tom292-293 & SSR & Suliman-Pollatschek et al. 2002 & $\begin{array}{l}\text { ATGTACTCTAATGGATGTTT } \\
\text { ATTCATAGCATTGTCATAGG }\end{array}$ & - & 47 \\
\hline Tom160-161 & SSR & Suliman-Pollatschek et al. 2002 & $\begin{array}{l}\text { TGCTGAAGAATACAATGTTACC } \\
\text { ATTGTTGGATGCTCAGTTTG }\end{array}$ & - & 48 \\
\hline Tom61-62 & SSR & Suliman-Pollatschek et al. 2002 & $\begin{array}{l}\text { GGCAAAGAAGGACCCAGAGC } \\
\text { GGTGCCTAAAAAAGTTAAAT }\end{array}$ & - & 48 \\
\hline U3-2 & SCAR & Present work & $\begin{array}{l}\text { AGTGGTTGGCGGATAGGTG } \\
\text { TTGGCAAGGTGGGAAAACT }\end{array}$ & 1200 & 55 \\
\hline T0707 & $\cos$ & http://www.sgn.cornell.edu & $\begin{array}{l}\text { TCGTGGATTATGGGCTTTCTT } \\
\text { GGTAAGGCTGCAACACATCA }\end{array}$ & 458 & 50 \\
\hline TG339 & RFLP & http://www.sgn.cornell.edu & $\begin{array}{l}\text { GAAACCTTACCCCTCTA } \\
\text { CGCTGTTTCTTGCCATTT }\end{array}$ & 436 & 46 \\
\hline TG652 & RFLP & http://www.sgn.cornell.edu & $\begin{array}{l}\text { CGGGGATCTGATAAGGAAGG } \\
\text { ATAAGGGATCGTCAAGGAGTAACA }\end{array}$ & 542 & 59 \\
\hline $\mathrm{T} 1405$ & $\operatorname{COS}$ & http://www.sgn.cornell.edu & $\begin{array}{l}\text { CACCAACAACTAGCCCTTGA } \\
\text { AAGCAATTCCTCCAGCTTCA }\end{array}$ & 535 & 55 \\
\hline cLEC7B23 & EST & http://www.sgn.cornell.edu & $\begin{array}{l}\text { GGAGAACACGGCTACCTCAG } \\
\text { GGAGAACACGGCTACCTCAG }\end{array}$ & 600 & 55 \\
\hline CT173 & RFLP & http://www.sgn.cornell.edu & $\begin{array}{l}\text { TGAGCACGGTATTACGCAG } \\
\text { TTAGTAGTATGTGTGGCAGTCAC }\end{array}$ & 500 & 55 \\
\hline TG2FS/R & RFLP & http://www.sgn.cornell.edu & $\begin{array}{l}\text { TGTTGAAGAAGGCTCAGCAA } \\
\text { TGCCCCTGTATATCCCTCAG }\end{array}$ & 241 & 55 \\
\hline TG2FL/R & RFLP & http://www.sgn.cornell.edu & $\begin{array}{l}\text { CCTCAATCCCAGGAATTTGT } \\
\text { TGCCCCTGTATATCCCTCAG }\end{array}$ & 403 & 57 \\
\hline TG516 & RFLP & http://www.sgn.cornell.edu & $\begin{array}{l}\text { GGCACTTCGCAAAACTGAAT } \\
\text { GGTACGGCGGGTTTAAGAC0T }\end{array}$ & 349 & 55 \\
\hline cTOC-20-K10 & EST & http://www.sgn.cornell.edu & $\begin{array}{l}\text { TGTGGTTTGCTTCATCTTGC } \\
\text { ACCAACACTCTTGGGGACAC }\end{array}$ & 360 & 56 \\
\hline cLEC-80-N18 & EST & http://www.sgn.cornell.edu & $\begin{array}{l}\text { CGTATCTTTGGGTGCCATTT } \\
\text { CAGGGCGATTAAACCAGAAA }\end{array}$ & 260 & 56 \\
\hline
\end{tabular}

Therefore, we selected seven SSRs mapped on chromosome 4 and two of them, Tom316 and Tom332, revealed length polymorphisms between $\mathrm{MM}$ and
R28 on $6 \%$ polyacrylamide gel. Polymorphism of the SSR marker Tom316 was also detectable on $2.5 \%$ agarose gel (Fig. 1). 

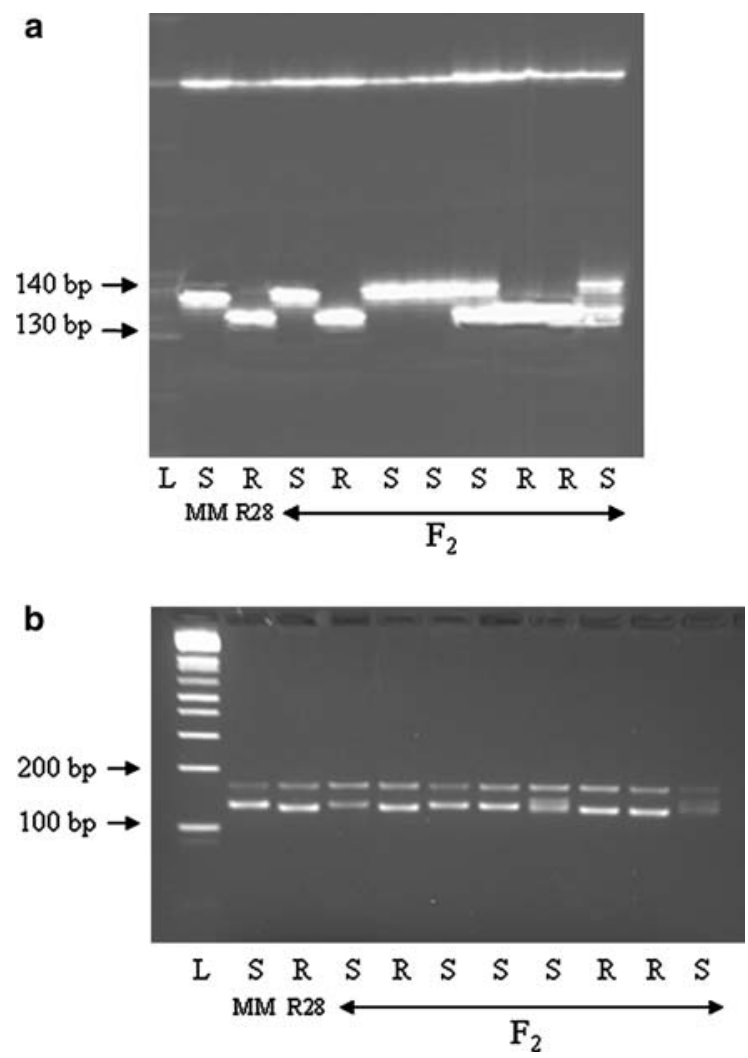

Fig. 1 SSR marker Tom316 tested on the susceptible (S) parent Moneymaker (MM), the resistant (R) parent R28 and eight $F_{2}$ individuals. Co-dominant length polymorphism is revealed on both $6 \%$ polyacrylamide gel (a) and $2.5 \%$ agarose gels (b). Lane $\mathrm{L}$ (ladder) points the molecular weight (bp)

All the ol-2 linked markers previously identified were used to search for polymorphisms between MM and R28. We failed to amplify the SCAU $3_{1500}$ SCAR sequence with the primers published by De Giovanni et al. (2004), thus new primers were designed. The amplification product, named U3-2, was subsequently digested and converted into a co-dominant CAPS marker, U3-2HhaI. Three out of the eight ol-2 linked AFLP $^{\circledR}$ markers so far reported, E34M61-270, E40M56-90 and E41M32-390, showed polymorphism between MM and R28.

By screening the $\mathrm{F}_{2}$ population of $\mathrm{MM}$ and $\mathrm{R} 28$ with the three polymorphic AFLP $^{\circledR}$ markers, the CAPS marker U3-2HhaI and the two SSR Tom316 and Tom332, a map of the ol-2 chromosomal region was constructed and integrated with the ol-2 maps reported by De Giovanni et al. (2004) and Ricciardi et al. (2007) (Fig. 2). Remarkably, almost identical segregation patterns were observed for nearly all the
Fig. 2 Integrated linkage map of the $\mathrm{Ol}-2$ locus region on tomato chromosome 4. Genetic distances were estimated by using Kosambi's mapping function

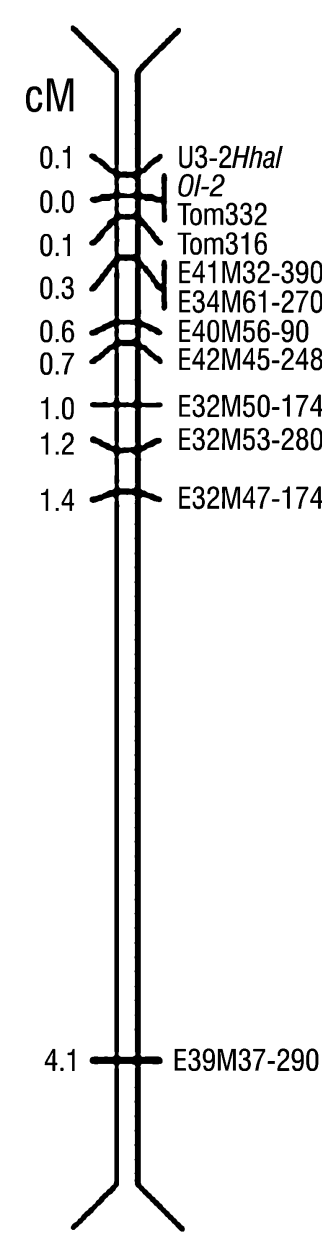

markers and the resistance, indicating that the ol-2 gene is located in a chromosomal region characterized by recombination suppression.

Physical co-localisation of the ol-2 gene and tomato mlo-homologue(s)

As both the genetic and phytopathological features of the ol-2-associated resistance mimic the well-characterized mlo-based resistance in barley, it is logical to argue that $o l-2$ is likely a $m l o$ homologue. By inspecting the tomato EST collection, two tomato ESTs (cLEC-80-N18 and cTOC-20-K10) were identified that are homologous to barley mlo. Unfortunately, genetic mapping of these two ESTs in the $\mathrm{F}_{2}$ population was hampered by the lack of polymorphism between MM and R28. To visualize the relative chromosomal location of the $\mathrm{ol}-2$ gene and tomato mlohomologue(s), we first screened the Heinz BAC 
library with PCR primers amplifying the tomato mlohomologous ESTs cLEC-80-N18 and cTOC-20-K10 (Table 1). Two BAC clones, 184L18 and 205G16, were identified, which were positive for both the ESTs. These two BAC clones were further inspected for the presence of the ol-2 linked SCAR sequence U3-2. Remarkably, both BACs were positive for the U3-2 sequence, suggesting the co-localization of the ol-2 gene with mlo homologue(s). In addition to the expected PCR fragment of $1200 \mathrm{bp}$ for the U3-2 sequence, other amplification products were obtained, indicating that the two BACs contain repetitive sequences.

FISH of 184L18 and 205G16 BACs on pachytene chromosomes of tomato revealed in both cases major signals on chromosome 4 , in the heterochromatin block of the short arm near the centromere (Fig. 3). In spite of blocking the BAC probes with Cot100 repetitive DNA, we also found small signals in heterochromatic regions of other chromosomes, which indicate that the BACs are rich in pericentromeric heterochromatic specific dispersed repeats. Repeat signals were more abundant for 184L18 (Fig. 3). As the ol-2 gene is located on chromosome 4 around the centromere (De Giovanni et al. 2004), the presence of tomato $m l o$-homologue(s) in the pericentromeric heterochromatin of the same chromosome further suggests that $o l-2$ is a mlo-homologue.

\section{Discussion}

Although several powdery mildew resistance genes have been reported, most of the current commercial tomato cultivars are susceptible to powdery mildew. The ol-2 source of resistance, which originates from the cultivated tomato species $S$. lycopersicum, might allow circumvention of linkage drag problems which are encountered during the transfer of wild tomato resistance genes into cultivated backgrounds. On the other hand, the genetic relatedness between the donor parent and elite genotypes complicates the identification of polymorphic markers to be used for MAS breeding programmes. This was demonstrated by the failure in trying to convert several sequences located on the ol-2 chromosomal region into PCR markers.

Suliman-Pollatschek et al. (2002) reported percentages of polymorphism within S. lycopersicum were $52 \%$ for SSR, $10.8 \%$ for AFLP $^{\circledR}$ and $5 \%$ for RFLP

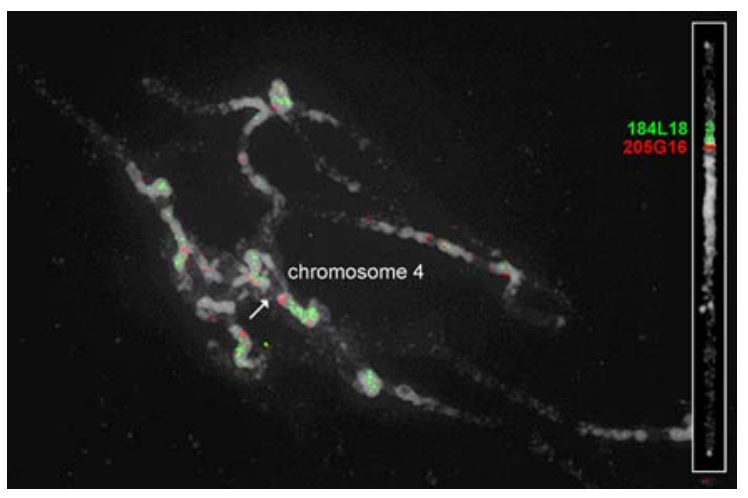

Fig. 3 FISH signals of the BAC clones 184L18 (labelled with FITC-dUTP) and 205G16 (labelled with Cy3.5-dCTP). The BACs display small and variable signals, close together, in the heterochromatic area near the centromere of chromosome 4 . 205 G16 gives a major focus next to the centromere and few minor signals more distally, whereas $184 \mathrm{~L} 18$ produces a variable number of smaller foci in the whole pericentromeric heterochromatic region. Some of the green and red signals overlap giving yellow fluorescence. Both BACs also give some background signals in heterochromatin areas of other chromosomes, due to cross hybridization of the repetitive sequences in the labelled BAC probe

markers. The higher variation of SSR loci was demonstrated by the present study, in which two out of seven SSR markers tested revealed length polymorphisms between MM and R28.

The three markers identified in this work can be easily obtained (the SSR marker Tom316 requires a simple PCR reaction and visualization on agarose gel) and are not patented, thus can be freely and conveniently applied for MAS in breeding programmes. Furthermore, their co-dominant nature will allow breeders to select directly for the presence of the recessive ol-2 allele.

In this study, BAC library screening and FISH analyses were used to demonstrate the co-localization of an ol-2 linked marker with mlo orthologue(s) in the pericentromeric heterochromatic region of the short arm of tomato chromosome 4. Amplification of the U3-2 sequence by using BAC DNA as a template was invariably accompanied by the presence of multiple PCR amplification. However, when genomic DNA was used as PCR template, only one PCR fragment was observed. It seems that primer mismatches occur during PCR amplification only with the BAC DNA as template. Multiple PCR amplifications obtained by using the U3-2 primer pair suggests that the BACs 
contain repetitive sequences, which are known to occur with very high frequency in heterochromatic regions. The abundance of repetitive sequences also explains the presence of multiple weak hybridization signals obtained with FISH analyses. On the other hand, the presence of discrete PCR fragments with the expected molecular weight for the two-tomato mlo ESTs suggests the presence of only one intact mlolike gene sequence. Although heterochromatin has been classically depicted as a gene poor region of the genome, our findings are in accordance with a growing body of evidence which shows that genes resident in heterochromatin can indeed encode essential functions (Nagaki et al. 2004; Rossi et al. 2007).

In tomato, the actual ratio of genetic and physical distance varies considerably depending on the chromosomal region. In the $T m-2 a$ region, close to the centromere of chromosome $9,1 \mathrm{cM}$ corresponds to more than five million base pairs (Pillen et al. 1996), whereas for the chloronerva gene region, located in the euchromatin of chromosome 1 , the ratio of genetic to physical distance is only $160 \mathrm{~kb}$ per $1 \mathrm{cM}$ (Ling et al. 1999). By determining frequency and distribution of recombination nodules on tomato synaptonemal complexes, Sherman and Stack (1995) observed a much lower frequency of recombination nodules in heterochromatic regions around the centromeres compared to euchromatin. Occurrence of recombination suppression near the centromere is reported also for other plant species (Tanksley et al. 1992; Drouaud et al. 2006). Therefore, the observed clustering of ol-2 linked markers can well be explained by their localization in the pericentromeric heterochromatin of chromosome 4 . The low ratio between genetic and physical distance does not favour ol-2 positional cloning, as it could require the screening of very large segregating populations and extensive chromosome walking.

In addition to the similarity of $o l-2$ and mlo resistances for both genetic (recessive) and phytopathological (papilla-based mechanism) characteristics, BAC screening and FISH data in this study indicated the genetic and cytogenetic co-localization of the ol2 gene with tomato mlo-homologue(s). All of this evidence strongly suggests that ol-2 is likely a mlo homologue. We are currently following a homology-based cloning approach for $o l-2$ isolation as an alternative to positional cloning.
Open Access This article is distributed under the terms of the Creative Commons Attribution Noncommercial License which permits any noncommercial use, distribution, and reproduction in any medium, provided the original author(s) and source are credited.

\section{References}

Bai Y, Huang CC, van der Hulst R, Meijer-Dekens F, Bonnema G, Lindhout P (2003) QTLs for tomato powdery mildew resistance (Oidium lycopersici) in Lycopersicon parviflorum G1.1601 co-localize with two qualitative powdery mildew resistance genes. Mol Plant Microbe Interact 16:169-176

Bai Y, Feng X, van der Hulst R, Lindhout P (2004) A set of simple PCR markers converted from sequence specific RFLP markers on tomato chromosomes 9 to 12. Mol Breed 13:281-287

Bai Y, van der Hulst R, Bonnema G, Thierry CM, MeijerDekens F, Niks RE, Lindhout P (2005) Tomato defence to Oidium Lycopersici: dominant $\mathrm{Ol}$ genes confer isolatedependent resistance via a different mechanism than recessive ol-2. Mol Plant Microbe Interact 18:354-362

Brugmans B, van der Hulst R, Visser RGF, Lindhout P, van Eck HJ (2003) A new and versatile method for the successful conversion of AFLP markers into simple locus markers. Nucleic Acids Res 31:e55

Budiman MA, Mao L, Wood TC, Wing RA (2000) A deep-coverage tomato BAC library and prospects toward development of an STC framework for genome sequencing. Genome Res 10:129-136

Büschges R, Hollricher K, Panstruga R, Simons G, Wolter M, Frijters A, van Daelen R, van der Lee T, Diergaarde P, Groenendijk J, Töpsch S, Salamini F, Schulze-Lefert P (1997) The barley mlo gene: a novel control element of plant pathogen resistance. Cell 88:695-705

Chang SB (2004) Cytogenetic and molecular studies on tomato chromosomes using diploid tomato and tomato monosomic additions in tetraploid potato. $\mathrm{PhD}$ thesis, Wageningen University

Ciccarese F, Amenduni M, Schiavone D, Cirulli M (1998) Occurrence and inheritance of resistance to powdery mildew (Oidium lycopersici) in Lycopersicon species. Plant Pathol 47:417-419

De Giovanni C, Dell'Orco P, Bruno A, Ciccarese F, Lotti C, Ricciardi L (2004) Identification of PCR-based markers (RAPD, AFLP) linked to a novel mildew resistance gene (ol-2) in tomato. Plant Sci 166:41-48

Drouaud J, Camilleri C, Bourguignon P, Canaguier A, Berard A, Vezon D, Giancola S, Brunel D, Colot V, Prum B, Quesneville H, Mezard C (2006) Variation in crossingover rates across chromosome 4 of Arabidopsis thaliana reveals the presence of meiotic recombination "hot spots". Genome Res 16:106-114

Jones H, Whipps JM, Gurr SJ (2001) The tomato powdery mildew fungus Oidium neolycopersici. Mol Plant Pathol 2:303-309

Kiss L, Cook RTA, Saenz GS, Cunnington JH, Takamatsu S, Pascoe I, Bardin M, Nicot PC, Sato Y, Rossman AY (2001) 
Identification of two powdery mildew fungi, Oidium neolycopersici sp. Nov., and O. lycopersici, infecting tomato in different parts of the world. Mycol Res 105:684-697

Kozik E (1993) Resistance to powdery mildew Oidium lycopersici in tomato. Tomato Genet Coop Rep 43:26

Lindhout P, van der Beek JG, Pet G (1994) Wild Lycopersicon species as sources for resistance to powdery mildew (Oidium lycopersicum): mapping of the resistance gene $\mathrm{Ol}-1$ on chromosome 6 of L. hirsutum. Acta Hortic 376:387-394

Ling HQ, Koch G, Bäumlein H, Ganal MW (1999) Map-based cloning of chloronerva, a gene involved in iron uptake of higher plants encoding nicotianamine synthase. Proc Natl Acad Sci USA 96:7098-7103

Miller JC, Tanksley SD (1990) RFLP analysis of phylogenetic relationships and genetic variation in the genus Lycopersicon. Theor Appl Genet 80:437-448

Nagaki K, Cheng Z, Ouyang S, Talbert PB, Kim M et al (2004) Sequencing of a rice centromere uncovers active genes. Nat Genet 36:138-145

Piffanelli P, Zhou F, Casais C, Orme J, Jarosch B, Schaffrath U, Collins NC, Panstruga R, Schultze-Lefert P (2002) The barley MLO modulator of defence and cell death is responsive to biotic and abiotic stress stimuli. Plant Physiol 129:1076-1085

Pillen K, Ganal MW, Tanksley SD (1996) Construction of a high-resolution genetic map and YAC-contigs in the tomato Tm.2a region. Theor Appl Genet 93:228-233

Ricciardi L, Lotti C, Pavan S, Bai Y, Lindhout P, De Giovanni C (2007) Further isolation of AFLP and LMS markers for the mapping of the $\mathrm{Ol}$-2 locus related to powdery mildew (Oidium neolycopersici) resistance in tomato (Solanum lycopersicum L.). Plant Sci 172:746-755

Rossi F, Moschetti R, Caizzi R, Corradini N, Dimitri P (2007) Cytogenetic and molecular characterization of heterochromatin gene models in Drosophila melanogaster. Genetics 175(2):595-607
Rozen S, Skaletsky J (2000) Primer3 on the WWW for general users and for biologist programmers. Methods Mol Biol 132:365-386

Sherman JD, Stack SM (1995) Two-dimensional spreads of synaptonemal complexes from solanaceous plants. VI. High-resolution recombination nodule map for tomato (Lycopersicon esculentum). Genetics 141:683-708

Suliman-Pollatschek SS, Kashkush K, Shats H, Hillel J, Lavi U (2002) Generation and mapping of AFLPs, SSRs and SNPs in Lycopersicon esculentum. Cell Mol Biol Lett 7:583-597

Tanksley SD, Ganal MW, Prince JP, De Vicente MC, Bonierbale MW, Broun P, Fulton TM, Giovannoni JJ, Grandillo S, Martin GB, Messeguer R, Miller JC, Miller L, Paterson AH, Pineda O, Roder MS, Wing RA, Wu W, Young ND (1992) High density molecular linkage maps of the tomato and potato genomes. Genetics 132:1141-1160

Van Ooijen JW, Voorrips RE (2001) JoinMap 3.0., software for the calculation of genetic linkage maps. Plant Research International, Wageningen, The Netherlands

Young ND, Tanksley SD (1989) RFLP analysis of the size of chromosomal segments retained around the $T m$ - 2 locus of tomato during backcross breeding. Theor Appl Genet 77:353-359

Zeven AC, Knott DR, Johnson R (1983) Investigation of linkage drag in near isogenic lines of wheat by testing for seedling reaction to races of stem rust, leaf rust and yellow rust. Euphytica 32:319-327

Zhong XB, Bodeau J, Fransz PF, Williamson VM, van Kammen A, de Jong JH, Zabel P (1999) FISH to meiotic pachytene chromosome of tomato locates the root-nematode resistance gene $M i-1$ and the acid phosphates gene Aps- 1 near the junction of euchromatin and pericentromeric heterochromatin of chromosome arms $6 \mathrm{~S}$ and $6 \mathrm{~L}$, respectively. Theor Appl Genet 98:365-370 